\title{
ARTICLE
}

\section{We've Been Framed! \\ Ends, Means, and the Ethics of the Grand(iose) Challenges}

\author{
Donna Riley \\ Picker Engineering Program, Smith College, driley@smith.edu
}

Since the United States' National Academy of Engineering's Grand Challenges were first publicly articulated in 2008, engineering educators have used its ideas to motivate their work. While there is a sense of moral imperative around pursuing selected Challenges, work that critically examines the ethics of the Grand Challenges has so far been rare. In this paper, examining the process surrounding the framing of the Grand Challenges generates a series of ethical questions about both the specifics of the Challenges and the processes that gave rise to them. A Grand Challenges lesson plan for classroom implementation focuses students on the ethics of problem framing, and the consideration of social justice questions as an integral part of professional ethics.

KEYWORDS: critical pedagogy, engineering for everyone, ethics, Grand Challenges, National Academy of Engineering, problem framing, technology means and ends

\section{INTRODUCTION}

Since the National Academy of Engineering (NAE) first publicly articulated the Grand Challenges for Engineering ${ }^{1}$ in 2008, engineering educators in the United States have responded explicitly by creating "Grand Challenge" courses (Johnson \& Siller, 2010; Ross, 2010; Savilonis, Spanagel \& Wobbe, 2010) and curricula for both $\mathrm{K}-12$ and undergraduate students (Bottomley, Lavelle, \& Martin-Vega, 2010; Rippon \& Collowfellow, 2010), and by utilizing the Grand Challenges to bolster arguments for working toward more integrated, multidisciplinary, development-and-sustainability focused approaches (Foster \& Heeney, 2009; Heun \& VanderLeest, 2008; White, Crawford, Wood, \& Talley, 2010; Zhang, Vanasupa, Zimmerman, \& Mihelcic, 2010).

For engineering educators concerned about liberal education for engineers, the Grand Challenges lend prestige and political weight to the broader efforts around multidisciplinary approaches, and around the incorporation of ecological and human welfare into engineering education. Many if not most of the Challenges (see Table 1) relate in some way to sustainability or humanitarian efforts, and most require holistic thinking that transcends the narrow traditional disciplines of engineering (NAE, 2011a).

For those interested in engineering ethics and the delivery of engineering ethics curricula, the Grand Challenges offer a rich field of proposals. While ethical questions associated with many of the

\footnotetext{
${ }^{1}$ Editors' note: The capitalized, non-italicized forms of "Grand Challenges" and "Challenges" found throughout this paper refer to the broader body of work stemming from the original 2008 NAE Publication. Where the actual publication is inferred, the terms are presented in italics.
} 
topics have been addressed elsewhere (Brown \& Schmidt, 2010; Bostrom, 2003; Brey, 2009; Gardiner, Caney, \& Jamieson, 2010; Goodman, 1998; Traer, 2009), the descriptions of the Challenges mostly do not include any ethical analysis, let alone from a standpoint of social justice.

This article, along with the others in this special issue, takes the risk of asking some hard questions of the Grand Challenges. Underlying the Grand Challenges project is a presumption that, having been selected, the fourteen Challenges are not only important undertakings, but also that they should go forward. But are they necessarily morally imperative? Are they necessarily for the greater good? Do they promote or hinder social justice? Ought they be undertaken at all? Such questions are a place to begin engaging the ethics of the Grand Challenges.

Table 1:

Fourteen "Grand Challenges" of Engineering

Make solar energy economical

Provide energy from fusion

Develop carbon sequestration methods

Manage the nitrogen cycle

Provide access to clean water

Restore and improve urban infrastructure

Advance health informatics

Engineer better medicines

Reverse-engineer the brain

Prevent nuclear terror

Secure cyberspace

Enhance virtual reality

Advance personalized learning

Engineer the tools of scientific discovery
It may be that engineering educators are, in some sense, afraid to ask some of these questions. Many of us most likely to ask the ethical questions are also those who would advocate for the incorporation of holistic and multidisciplinary approaches to engineering. The larger project of the Grand Challenges, the discourse and buzz generated, politically moves that advocacy forward. Why risk alienating NAE members and others on the Grand Challenges committee, powerful allies in the engineering education reform effort?

As an engineering educator committed to social justice, I offer this analysis because examining the Grand Challenges in light of engineering ethics and social justice can open up a set of larger questions that move us forward in defining the parameters of purposeful and significant work for the engineering profession in society. In this sense, backers of the Grand Challenges project who are allies of engineering education reform will recognize the discussion of ethics as an invitation to a kind of reflexive practice (Finlay \& Gough, 2003), deepening the conversation by reflecting critically on the Challenges and the processes that produced them.

The NAE has defined the scope of several problems that constitute the "grand" work of the profession in this century. This paper seeks to describe and analyze the Grand Challenges from a social justice perspective, posing ethics questions about the actors, the selection process and criteria, and the means and ends of the Challenges themselves:

- What does it mean to frame out a set of "Grand Challenges" in engineering? What does it say about the role of technology in society, or the role of engineering? How might other understandings about technology in society have led to different framings?

- Who participated in this framing, and by what process? Who was left out of the deliberations, or given a lesser role?

- Why are the Challenges framed as morally imperative or at least for the greater good? Should they be framed this way? Are the ends even desirable, and for whom? Why are certain technologies included, and not others? 
- What ethical consideration was given, or needs to now be given, to the means by which we might strive to meet such challenges?

As this paper examines these four broad areas, it produces a set of questions for further exploration in both engineering ethics and engineering studies. The paper closes with a sketch of a classroom implementation that guides students in asking similar questions of the Grand Challenges as they explore them topically, focusing students on the ethics of problem framing, and the consideration of social justice questions as an integral part of professional ethics.

\section{FRAMING}

Engineering Studies scholar Gary Downey (2005) among others has pointed out that problem framing is as important as it is neglected in engineering education. Engineers are trained not to pay attention to the underlying structures that define and shape our work. Rather we tend to concede to others the work of framing problems we solve in a "given: find" format. To put it another way, sociologist Robert Zussman in his 1985 study of engineers observed that

The technical rationality that is the engineer's stock-in-trade requires the calculation of means for the realization of given ends. But it requires no broad insight into those ends or their consequences. Engineers are aware of, are trained to be aware of, these limitations; insofar as they do consider ends, they cease to act as engineers. (pp. 122-3)

Zussman calls out the narrow framing of engineering ethics as not concerned with the ends of one's work. By abdicating responsibility for problem framing, engineers are allowing our work to be framed-and are potentially being set up to commit unjust acts. The title of this piece reflects the voice of engineers waking up to the realization of their involvement in an unjust project, crying "we've been framed!" never realizing that we are in fact far from innocent.

The Grand Challenges project sets forth ends for engineers, implicitly invoking moral imperatives, but never articulating an ethical argument for pursing these ends. Here I seek to bring fundamental questions from the field of ethics, and in particular, from social justice traditions within ethics, to bear on the Grand Challenges in order to illuminate the ways in which power operates through the structure of the NAE, the profession, and engineering education in framing what engineering is, and what engineering can be.

It is not my intent to produce an objective or systematic analysis of the Grand Challenges, because that would require pretending that I am somehow outside or above the processes that produce such a report. As an engineer and engineering educator I am embedded in the structures of power that produced the report. Quite directly, I have served on two advisory boards to the NAE, though neither worked on the Grand Challenges. As an engineer committed to social justice, I seek to resist injustice within these structures, even as I am a part of them.

Thus my intent here is to be transparent about my own commitments and assumptions as I seek to shine the light on hidden commitments and assumptions of the Grand Challenges project. I want to understand how power works throughout the engineering profession, and my own practice is no exception. As a queer female engineering professor at a small private liberal arts college for women, I enjoy an odd mix of simultaneous dismissal and prestige from colleagues and in the profession. I am an active participant in the Engineering, Social Justice, and Peace network, whose values and commitments are out in the open and also out of the mainstream. 
The method used for my analysis is document studies, a qualitative method in the frame of naturalistic inquiry (as opposed to positivist inquiry), used by (inter alia) historians to analyze primary sources (Lincoln \& Guba, 1985). An idiographic description and analysis of the Grand Challenges are presented together below, organized around the four questions I posed in the introduction. These questions, grounded in the literature on engineering and social justice, reflect my own subjectivity: certain assumptions of the Challenges are visible to me and able to be questioned, while others not. Locating this piece in a special issue on the topic of the Grand Challenges allows for analysis from other vantage points that I hope, taken together, will create a more complete analysis.

I offer a particular framing of "ethics" here that reflects a movement of scholars in engineering ethics seeking to broaden the boundaries of this field. Among these scholars, Johnson and Wetmore (2007) argue for better integration of Science and Technology Studies (STS) with engineering ethics, incorporating ideas from STS like co-construction of technology and society and broadening the scope of engineering ethics beyond individual professional acts to include societal level problems. Such integration also makes possible the incorporation of critical perspectives, used throughout my analysis because of their particular relevance to social justice.

\section{Who Chose the Challenges?}

The committee that developed the Grand Challenges comprised 18 people $(12$ engineers and 6 others, all in scientific fields), only three of whom were women (only one of the women was an engineer). About a third was from academia, a third from government/public service, and a third from industry, with a nearly exclusive emphasis on inventor/entrepreneur/CEOs in that sector. Some committee members had work and/or life experience outside the United States, including in Africa, Asia, Latin America, and the Middle East, but all or nearly all had strong ties to the United States, limiting the range of international perspectives privileged to inform the Grand Challenges, which are both national and global in scope. All committee members were over 35 with impressive career records, including at least 12 members of the National Academies. Data on other axes of diversity such as race and ethnicity were not available (NAE, 2011b).

Input was sought from the general public via the NAE website. The NAE boasts that over 1000 people from over 40 countries submitted comments (NAE, 2011c). However, reading the comments makes clear that the people who responded were not representative of the public at large but rather appeared to be from a relatively elite, science/technology oriented group connected in some direct or indirect way to the NAE. While the comments provided input to the Committee, it was ultimately the Committee Members who selected the Grand Challenges. Their choices were reviewed by a group of 49 reviewers; biographies are not provided in the NAE materials as they were for the Committee members, but it is worth noting that 26 of the 49 are members of the National Academies (NAE, 2011d).

Why were particular individuals chosen to participate on the Committee or as reviewers? Why were $100 \%$ of the Committee members scientists and engineers? Why were career accomplishments so central to the selection process? Does the prestige of the NAE, and of its members, lend grand-ness (or grandiosity?) to the Challenges?

At least some of the Grand Challenges relate very closely to the work of individual Committee members. For example, the emphasis on personalized medicine in "Engineer better medicines" reflects Craig Venter's interest in innovation in this area, exemplified by his controversial publication of his own genome (Levy et al., 2007). "Manage the nitrogen cycle" is a passion of Rob 
Socolow, whose work is cited in the write-up (NAE, 2008, pp. 16-18). He is also deeply involved with carbon sequestration, another one of the Challenges, where his work is referenced again (NAE, 2008 , pp. 13-15, 51). This raises a question about framing-why the heavy emphasis on personalized medicine in "Engineer better medicines?" Why wasn't "Develop carbon sequestration methods" more broadly defined as addressing climate change, with a more complete range of methods to address the problem included? How were the specific climate-related challenges selected: "Provide energy from fusion;" "Make solar energy economical;" and "Develop carbon sequestration methods?" What are the assumptions-for example, about economics and the position of solar technology (it's presently too expensive; there's nothing wrong with our market system, we don't need to internalize environmental externalities, there is nothing wrong with our energy policy... we just need to make it cheaper)—that go into defining and selecting a particular Challenge? Why were other energy methods (wind, hydrogen, biofuels-or for that matter, energy efficiency and conservation) left out? By what process were they eliminated?

It is not surprising that individuals on a committee would advocate for issues they are passionate about; naturally they consider the issues that have become their life's work to be important. Thus, it is perhaps completely expected that "Engineer the tools of scientific discovery" would be a priority among a group of $100 \%$ scientists and engineers. However, this highlights the ethical importance of who participated and who did not in shaping the Challenges. What is not considered because of who was not at the table? Would a different group with different personal priorities produce different challenges? If the group were more representative of a cross-section of the profession, or of the nation as a whole, or of the global population, how would the Challenges be differently defined?

\section{UNDERLYING ASSUMPTIONS: TECHNOLOGY AND SOCIETY}

The framing of the Grand Challenges reflects a number of assumptions about the role of technology in society, as well as the role of engineering as a profession. Four questions are posed here in order to examine some of these assumptions.

1. Is Engineering Grand? First, there is the "grand" framing-engineering is being put forward as a noble profession that can address important problems of the day and of the future. This is of course a kind of self-promotion that seems perhaps more grandiose than grand. Even within the Challenges selected, engineers have played problematic roles, and are not necessarily heroes. For example, engineers are given a role here to "Prevent nuclear terror," but no mention is made of engineers' role in inventing nuclear terror in the first place (Norris, 2002). The argument for "Advance health informatics" is in part to respond to attacks from biological and chemical weapons-never mind U.S. engineers' role in advancing the state of the art in production and delivery (Cirincione, Wolfsthal, \& Rajkumar, 2005). The argument could be made that engineers' involvement in developing these horrors increases our responsibility now to rise to the Grand Challenges-but such an argument is nowhere in evidence. It would require a certain level of humility and frank discussion that falls outside the current framing.

2. Is High-tech Always Better than Low-tech? The Grand Challenges are future-oriented and emphasize innovation and development of new solutions that feature high technology. There is little place for "mundane science" here (Kammen \& Dove, 1997). For example, in addressing the world's need for clean water, the discussion emphasizes high-tech solutions such as nanofiltration and desalination (NAE, 2008, pp. 19-21) over widely available low-tech solutions such as filtration with local materials (Colwell et al., 2003). 
3. Is Technology Always Progress? Innovation is presented as progress, and there is no hesitation around the introduction of new technologies in pursuit of the Grand Challenges. As noted above, existing technology is passed over for the shiny new high-tech thing. Embedded in this notion of progress is an assumption of technological determinism, that "Throughout human history, engineering has driven the advance of civilization" (NAE, 2008, p. 1). In this one-way trajectory, technology pushes history forward. An alternative view would be the idea of co-construction of technology and society (Taylor, 1995), in which social developments might emerge along with engineering developments, each influencing and giving rise to the other. Thus, we must not only ask about "ethical implications" of the Grand Challenges, as if technology drives or creates the need for ethics in a one-way relationship. We must also ask about the ethics of circumstances that give rise to the Challenges: at what point in history does the project emerge, in what country with what geopolitical agendas, with what kind of engineering workforce positioned how within the society? (Johnson \& Wetmore, 2007).

4. Is Technology an End in Itself? The uneven framing of the various Grand Challenges raises the question of purpose. Are some Challenges merely about demonstrating technological prowess, while others are directed toward solving a larger social problem or meeting humanitarian needs? The challenge to "Make solar energy economical" is extremely specific, and involves multiple goals: saving money/making the technology affordable, developing improved materials for energy capture and storage, meeting people's energy needs, and meeting larger sustainability goals. The criterion of affordability is not applied to fusion, the other energy technology whose development is a Grand Challenge; why is this value applied to one technology and not another? When a Grand Challenge presents technology as solving complex problems such as access to clean water, or meeting a need for "better medicines," it raises the question of whether these are at their core technological problems. Is it genetic technologies and personalized therapies that will improve medicine the most, or might we need to focus on changing economic, political, and social values to expand access and provide basic care to all?

\section{EndS: Should We Undertake the GRAND Challenges?}

Among the unasked questions regarding the ethics of the Grand Challenges is whether undertaking these challenges would be ethical in the first place, as well as whether these ought to be the highest priority efforts for the profession in society.

In the discussion of the Challenge to "Reverse-engineer the brain," the primary justification for this undertaking is improving artificial intelligence (AI) (NAE, 2008, pp. 34-36). Is this desirable? Who benefits? What are the risks, and who bears the costs? A side benefit (to the main goal of improving $\mathrm{AI}$ ) is the ability to address "brain disorders," though no critical thought is given to the social dynamics and power relations by which some ways of thinking are labeled "disordered"(Foucault, 2006). An understanding of these power relations might give us pause, asking again which brain "disorders" are to be cured, and who decides?

Finally it is pointed out that artificially intelligent brain implants could (among other things) help "crippled people to walk" (NAE, 2008, p. 34). The use of the word crippled is frankly shocking as it has been considered pejorative in the United States for decades. Both the use of the term and the suggestion that these brain implants are the "solution" to a "problem" of impairment disregards the social model of disability (Davis, 1996) which defines disability as a form of social oppression. One manifestation of this oppression is readily evident when infrastructure does not accommodate all people's forms of mobility, but rather limits access to enforce a particular norm (e.g., walking) and 
demands conformity to it (in this case, by going to the lengths of reverse-engineering the brain). From this perspective, "Universal design" might be a more socially just Grand Challenge.

Similarly, "Advance personalized learning" advocates for electronic delivery of learning without acknowledgment of the arguments put forth in response to the development of distance learning, of what is lost both in interpersonal interaction and in the corporatization and privatization of learning (Lieberwitz, 2002). An apparently un-ironic reference to The Matrix holds up Trinity's "downloading" into her brain a learning module on how to fly a helicopter as an ideal to be attained (Silver, 1999). However, considering the larger context of the film and its themes, this entire Grand Challenge is clearly problematic; Trinity and her colleagues are, after all, imprisoned in a virtual reality, and their goal is to resist the Artificially Intelligent machines that control their bodies and minds (Haslam, 2005).

What does the choice of certain ends imply about the means? Langdon Winner (1986) has identified the centralized power structures required for the development of nuclear power (which would extend here to fusion technologies). Who will be able to participate in the engineering projects identified, and in what capacities-as embedded corporate workers, as government employees, as contractors, as non-profit employees, or as independent professionals? Will engineers have autonomy to control the means of production? What latitude will they have to negotiate the ethical boundaries of a project? Some of these questions relate directly to the means, discussed further below, but to what extent does the shaping of the ends constrain the means?

\section{Means: How Should We Define And PuRsue the Challenges?}

Some Grand Challenges represent ends that are unlikely to be opposed by many-who wouldn't want to increase people's access to clean water, or prevent nuclear annihilation? However, what it means to achieve these goals and how one goes about achieving them raise important ethical questions that are largely unaddressed in the NAE's descriptions of the Challenges.

For example, the discussion of "Restore and improve urban infrastructure" highlights energy and environmental considerations as well as aesthetics, but does not consider the potential for these projects to displace populations with low social capital. Affordability of housing after improvements and linkages between infrastructure improvements and gentrification are not addressed. Whether a particular project to rebuild infrastructure can be considered ethical depends critically on careful attention to how vulnerable populations are affected, and whether and how they are able to participate meaningfully in the process so as to reap the project's potential benefits (NAE, 2008, pp. 22-24).

The description for "Engineer better medicines" briefly acknowledges ethical problems with privacy and affordability of personalized medicine. "Of course, a transition to personalized medicine is not without its social and ethical problems. Even if the technical challenges can be met, there are issues of privacy when unveiling a person's unique biological profile, and there will likely still be masses of people throughout the world unable to access its benefits deep into the century"(NAE, 2008, p. 32).

Why aren't privacy and access issues incorporated into the Challenge's framing? If a broader notion of "better" medicines were considered, one might, for example, include the problem of multinational corporations patenting indigenous medical knowledge, or "orphan" drugs that have been or could be developed by pharmaceutical companies, but investment is discontinued when it is clear that the drugs will not be profitable because a disease primarily affects poor people (Stix, 
2004). Thus, "Engineer better medicines" may be a worthy challenge, but how one goes about doing so, (and how one defines better, and for whom) matters.

The discussion of access to clean water begins to acknowledge that the core problem may not be technological, mentioning that "In many instances, political and economic barriers prevent access to water even in areas where it is otherwise available" (NAE, 2008, p. 19). However, this realization does not alter the problem framing or cause the Committee to reconsider the strong focus on desalination and nanofiltration. The problem is seen to be not at the level of problem definition, or even technological development, but at the level of implementation: "Even within a given country, clean, cheap water may be available to the rich while the poor have to seek out supplies, at higher costs, from intermediary providers or unsafe natural sources. Technological solutions to the world's water problems must be implemented within systems that recognize and address these inequities" (NAE, 2008, p. 21).

But this raises key questions-if the problem is political and economic, is the solution technological? If inequity is to be addressed, shouldn't engineers play a strong role in refusing water privatization schemes and other inequitable processes? Shouldn't current engineers involved in water privatization, dams that displace the poor, and other projects be called out as less than grand? The means by which engineers deliver clean water matters immensely. These important ethical issues are not discussed in the Challenge description beyond the text already quoted here. Indeed, Zussman (1985) would argue that in order to be considered members of a profession, engineers must recognize their responsibility extends beyond the technical and take up these questions addressing both the means and ends of our professional practice.

Finally the Grand Challenge of "Prevent nuclear terror" is curiously framed. In the wake of the dropping of the bombs on Hiroshima and Nagasaki, many recognized these events as acts of terror, because the bombs killed civilians living in areas that were not militarily significant in order to send a political message to others unaffected (Zinn, 1995). While any use of nuclear weapons can reasonably be considered terrorism by this definition (state terror if acted out by governmental authorities), the NAE's framing sees only those acting outside of governmental authority as "terrorists" to be deprived of nuclear weaponry. The means of "Prevent nuclear terror" include securing nuclear materials, surveillance of nuclear activity, deactivating bombs, and, oddly, two activities that are not preventive at all (cleanup/public communication and determining who was responsible) (NAE, 2008, pp. 37-39). This is a most unfortunate framing, as efforts for peace are not in the picture at all, even though building international and intercultural understanding has the potential to eliminate the need for nuclear weapons in the first place. Improving international or interpersonal relations can reduce the likelihood that authorized or unauthorized development and/or use of nuclear weapons would ever be considered worthwhile (and would likely also alter the language and framing of "nuclear terror"). George Catalano's (2004) call to engineers to contemplative action for peace would, in my view, constitute a Grander Challenge, more difficult yet morally transformative.

\section{TAKING TheSe QUeStIONS INTO THE CLASSROOM: LeSSON PLAN}

Here I provide a lesson plan for an introductory engineering course that includes both intended majors and non-majors. It could be adapted for other course contexts, both in terms of class content and classroom size. 


\section{Background Information on Class/Students}

The course in which this lesson has been offered, "Engineering for Everyone" is a design-based introduction to engineering in which students work in groups on a hands-on semester-long design project. Topics for the project vary from year to year, but the course in which the lesson plan was implemented focused on the world's water problems, and students designed and built drinking water purification systems, with particular attention to difference, power, and privilege operating in global development settings. The class had 22 students, with about half intending to major in engineering, and half taking the class for fun and exposure to a different discipline at a small private liberal arts college. Most were first-year students, but some were sophomores, juniors, and even seniors, with the upper-class students most likely to be majoring outside of engineering. The class met for 80 minute classes twice a week and one weekly three-hour hands-on session set aside for group meetings, lab, or shop work.. Students meet for 80 minute classes with one longer hands-on session each week set aside for group and lab or shop work. The Grand Challenges assignment is one of three essay assignments that address the social context of engineering; the others are a narrative of how an individual student sees their own values and goals fitting with the world of engineering, and an analysis of how technology and society are co-constructed, examining the case of a technology of their choice.

My overall pedagogical orientation is toward critical (feminist, anti-racist) pedagogies (Darder, Baltodano, \& Torres, 2008). In this setting of a course designed collectively by our faculty with shared responsibility for teaching, my practices align well with mainstream active learning approaches, but also include critical engagement with issues of power and privilege. Here the Grand Challenges unit is designed to help students critically question power relations in the field of engineering and in the production of the Grand Challenges themselves, asking whether the Challenges themselves and the means of the achieving them are socially just.

\section{Objectives}

The purposes of the Grand Challenges unit are to:

1) Familiarize students with the National Academy of Engineering and the aspirational Grand Challenges report as a means of understanding the profession.

2) Realize the importance of problem framing in engineering by critically examining the Grand Challenges as pre-framed problems.

3) Discover, Challenge, and Re-Imagine ways that engineering might be involved in addressing critical social and ecological problems.

4) Apply ethical frameworks to the broad social contexts in which engineers operate.

\section{Student Preparation}

Students explore the NAE website as their reading before class. It is a fully developed and rich source of information on the Grand Challenges. Students can also be assigned an additional background reading on engineering ethics that covers different values and principles that can be applied in analyzing ethics problems, or that material can be delivered in class. Reading questions that provide accountability for student reading include: "Explain the social and historical context of the NAE report. Who is the NAE, and what are they saying about engineering in the United States and in the world through this report?" and "What is the difference between consequentalist and deontological ethics?" 


\section{Class Activity}

1. Think Pair Share: (Students think to themselves about the questions for a moment, talk with a neighbor for a few minutes, and then pairs volunteer to share what they discussed.) What is the NAE and what does it do? Why do you think the NAE did a project called "Grand Challenges"? How might the project have been different if the challenges didn't have to be "grand"?

2. Large Group Discussion: Who decided what the Grand Challenges were? Do you think it would have been different if other groups of people were asked to decide what would be the important work of engineers in society? Who else might they have asked?

3. Role Play: Assign groups to represent different segments of society who were left out of framing the Grand Challenges. Brainstorm 3 challenges the group would most like to see addressed in the world. What can engineering do to address these challenges?

4. Large Group Discussion: How to approach problems in engineering ethics. Beginning with an example such as "Is it ethical to pick up a pine cone in a State Park?" or "Is it ethical to pick up money on the sidewalk?" students can learn to transform a gut answer into a formal ethical argument. Pushing students to articulate why they answer the way they do and identifying key values or principles they are applying to their case (e.g., "thou shalt not steal" or "the greatest good for the greatest number") helps them to understand how to analyze problems in ethics. Encourage them to think critically about what conditions or facts are most relevant to the situation (how much money is it? What species of pine?), and might affect their approach to the problem. Explain or have them read about the differences among consequentialist, deontological, virtue, and other types of ethical approaches. I find it useful to explain the categories first and then introduce flexibility by illustrating how ethicists might blend them or depart from them.

\section{Homework: Essay}

Choose one of the Grand Challenges as defined by the NAE, and provide an ethical analysis along one of the following two lines:

a) Whether or not the Challenge should be pursued.

b) How the challenge should be pursued. Are there ways to go about it that would be more ethical, or less ethical/unethical? Why? For whom?

Consider ethical arguments and counterarguments. Focus not so much on whether but why an action is ethical or unethical. Utilize different ethical frames of argument-ones that consider consequences, ones that consider duties, rights, or responsibilities, ones that consider values or virtues, etc.

\section{Evaluation Rubric for Homework}

The descriptions below refer to the highest achievable score of 4 points for each item. Descriptions for 3 , 2, and 1 point are not included here for length but can be used to clarify expectations for evaluation.

\begin{tabular}{|l|l|l|}
\hline Item & Score (0-4) & Comments \\
\hline WRITING QUALITY & & \\
\hline ARGUMENTATION & & \\
\hline ETHICS & & \\
\hline AVERAGE (sum/3) & & \\
\hline
\end{tabular}


WRITING QUALITY - Writing is clear, concise, and logical, with sufficient detail, free from casual language, grammatical errors and awkward sentence construction. Words are used correctly. Superfluous information omitted. Essay is well-structured with a clear introduction, development of thesis with supporting statements, and recapitulation that summarizes the main arguments. Document is professional in appearance, follows specified length guidelines, etc.

ARGUMENTATION - Sources are cited in APA format, including course readings and ethical frameworks used. Sources appropriately and sufficiently support argument. Support is specific and precise. Critical thinking is evident in consideration of multiple ethical frameworks and stakeholder perspectives. Counterarguments are anticipated and addressed. Statements are consistent within the context of the essay, without logical flaws. Avoids universalizing and oversimplification. Argument progresses logically and sequentially. Argument is persuasive and compelling. Argument demonstrates familiarity with the Grand Challenges and an understanding of how problem framing shapes the engineering profession.

ETHICS - Applicable moral concepts, rules, and principles are identified. Multiple ethical frames are applied correctly. The locus of disagreement is named, and facts and concepts brought to bear upon all possible resolutions. Alternative resolutions are considered where facts and concepts may change. Student provides evidence of deep reflection and iterative thinking about the Grand Challenges, including creative thought about how engineering can address critical social and ecological problems (with or without the Challenges).

\section{Discussion}

In a more expanded unit, or in a class where students are not familiar with ethics, students could ask people they know from different parts of their lives (technical and non-technical, peers and family, etc.) what they think the biggest challenges are for society.... And which ones do they think are ones that engineers or technology could help address.

These activities focus students on the ethics of problem framing (who wins and who loses when you choose one framing over another?), and on the consideration of larger social justice questions as an integral part of professional ethics as engineers. It raises early questions about process and inclusion as well as outcomes for different individuals or groups. The Grand Challenges are made to intersect with deep questions about technology in society, and in doing so students critically question a nationally authoritative body in the profession.

\section{Instructor Self-Evaluation}

This lesson plan was offered in spring 2012 to 22 students at Smith College. Two end-of-semester surveys and one mid-semester focus group conducted by an outside staff person asked students open-ended questions about the course (all variations on what is working well, and what would you change). In all three assessments, students spoke positively of "how she brings social justice and ethics to the forefront of our discussions of engineering." At the end of the semester ethics was the second-most frequently mentioned thing students thought worked well in the class (after the hands-on project). Students asked for clearer instructions on the essays in all three assessments, and one student wanted to make the essays more relevant to course material, while another asked for "less ethics." On balance, this was a successful assignment, though it can be modified in the future to clarify expectations for the assignment and strengthen its relevance to the course project. Because the course topic was the world's water problems, the connection to "Provide access to clean water" may have been clear, but not the connection to other Challenges. In any case, better 
communication around the connection between the Challenges essay assignment and the course theme should be sufficient to address this concern.

\section{CONCLUSION}

This inquiry has produced a number of questions for engineering ethics and engineering studies scholars to pursue further, and a lesson plan for teaching the Grand Challenges that focuses students on the ethics of problem framing, and the consideration of social justice questions as an integral part of professional ethics. Ultimately both pursuits question whether it is appropriate for the profession's priorities or for engineering education's priorities to be driven by the Grand Challenges project (to the extent that it is), or by other similar reports by authoritative bodies.

At a minimum, a less grandiose and more humble approach for the National Academies to take in the future would invite epistemologies and knowledges outside of engineering, including Science and Technology Studies, which has much to offer engineers' understanding of the role of technology in society. To further social justice goals, the processes that produce and disseminate these reports ought to become more democratic, more responsive and accountable to non-engineers in society, and more critically reflexive. Whether engineers and engineering educators concerned about social justice pay attention to these reports in the future may depend upon their ability to do just that.

\section{REFERENCES}

Bostrom, N. (2003). Ethical issues in advanced artificial intelligence. Retrieved from http://www.nickbostrom.com/ethics/ai.html

Bottomley, L., Lavelle, J., \& Martin-Vega, L. (2010, June). Broadening the appeal by changing the context of engineering education. ASEE Annual Conference and Exposition, Conference Proceedings.

Brey, P. (2009). Biomedical engineering ethics. In J. K. B. Olsen, S. A. Pedersen, \& V. F. Hendricks (Eds.), $A$ companion to the philosophy of technology [Blackwell Reference Online]. Retrieved from http://www.blackwellreference.com/public/book?id=g97814051460129781405146012

Brown, P. G., \& Schmidt, J. J., (Eds.). (2010). Water ethics. Washington, DC: Island Press.

Catalano, G. D. (2004, June). A peace paradigm for engineering education: A dissenter's view. ASEE Annual Conference Proceedings. 10945-10952.

Cirincione, J., Wolfsthal, J. B., \& Rajkumar, M. (2005). Deadly arsenals: Nuclear, biological, and chemical threats (2nd ed.). Washington, DC: Carnegie Endowment for International Peace.

Colwell, R. R., Huq, A., Islam, M. S., Aziz, K. M. A., Yunus, M., Khan, N. H., . . Russek-Cohen, E. (2003). Reduction of cholera in bangladeshi villages by simple filtration. Proceedings of the National Academy of Sciences, 100(3), 1051-1055.

Darder, A., Baltodano, M. P., \& Torres, R. D. (2008). The Critical Pedagogy Reader (2nd ed.). New York, NY: Routledge.

Davis, K. (1996). The social model of disability: Setting the terms of a new debate (Factsheet). Retrieved from Glasgow Centre for Inclusive Living website: http://www.gcil.org.uk/FileAccess.aspx?id=59

Downey, G. (2005). Are engineers losing control of technology? From "problem solving" to "problem definition and solution" in engineering education. Chemical Engineering Research and Design, 83(A6), 583-595.

Finlay, L., \& Gough, B. (2003). Reflexivity: A practical guide for researchers in health and social sciences. Malden, MA: Blackwell.

Foster, J., \& Heeney, A. (2009). The engineering science praxis sequence: Challenges and opportunities when integrating sustainable development into the engineering design classroom. ASEE Annual Conference and Exposition, Conference Proceedings. 
Foucault, M. (2006). Madness and civilization: A history of insanity in the Age of Reason. New York, NY: Routledge.

Gardiner, S., Caney, S., \& Jamieson, D. (Eds.). (2010). Climate ethics. New York, NY: Oxford University Press.

Goodman, K. W. (Ed.). (1998). Ethics, computing, and medicine: Informatics and the transformation of health care. New York, NY: Cambridge University Press.

Haslam, Jason W. (2005). Coded discourse: Romancing the (electronic) shadow in The Matrix. College Literature, 32(3), 92-115.

Heun, M., \& VanderLeest, S. (2008, June). Why a liberal and multidisciplinary education is needed to solve the energy crisis. ASEE Annual Conference and Exposition, Conference Proceedings.

Johnson, D., \& Wetmore, J. (2007). STS and ethics: Implications for engineering ethics. In E. J. Hacket, 0. Amsterdamska, M. Lynch, \& J. Wajcman (Eds.), The handbook of science and technology studies (pp. 567582). Cambridge, MA: MIT Press.

Johnson, G., \& Siller, T. (2010, June). A 21st century undergraduate engineering education program. ASEE Annual Conference and Exposition, Conference Proceedings.

Kammen, D. M., \& Dove, M. R. (1997). The virtues of mundane science. Environment, 39(6), 10-15, 38-41.

Levy, S., Sutton, G., Ng, P. C., Feuk, L., Halpern, A. L., Walenz, B. P., . . Venter, J. C. (2007). The diploid genome sequence of an individual human. PLoS Biology, 5(10), e254. Retrieved from http://www.plosbiology.org/article/info:doi/10.1371/journal.pbio.0050254

Lieberwitz, R. L. (2002). The corporatization of the university: Distance learning at the cost of academic freedom? Boston University Public Interest Law Journal, 12, 73-135.

Lincoln, Y. S., \& Guba, E. G. (1985). Naturalistic inquiry. Beverly Hills. CA: Sage Publications.

National Academy of Engineering. (2008). Grand challenges for engineering. Washington, DC: National Academies Press. Retrieved from http://www.engineeringchallenges.org/?ID=11574

National Academy of Engineering. (2011a). Grand challenges for engineering: Grand challenges. Retrieved from http://www.engineeringchallenges.org/cms/challenges.aspx

National Academy of Engineering. (2011b). Grand challenges for engineering: Committee. Retrieved from http://www.engineeringchallenges.org/cms/7124.aspx

National Academy of Engineering (2011c). Grand challenges for engineering: Ideas from the public. Retrieved from http://www.engineeringchallenges.org/cms/7124/7169/9521.aspx

National Academy of Engineering (2011d). Grand challenges for engineering: Review process. Retrieved from from http://www.engineeringchallenges.org/cms/7124/7169/9342.aspx

Norris, R. S. (2002). Racing for the bomb: General Leslie R. Groves, the Manhattan Project's indispensible man. South Royalton, VT: Steerforth Press.

Rippon, S., \& Collofellow, J. (2010, June). Camping the way to higher retention rates. ASEE Annual Conference and Exposition, Conference Proceedings.

Ross, P. (2010, June). Space exploration: Science, engineering and social impact in a freshman technical communication course. ASEE Annual Conference and Exposition, Conference Proceedings.

Savilonis, B., Spanagel, D., \& Wobbe, K. (2010, June). Engaging students with great problems. ASEE Annual Conference and Exposition, Conference Proceedings.

Silver, J. (Producer), Wachowski, A. \& Wachowski, L. (Directors). (1999). The matrix [DVD]. Burbank, CA: Warner Home Video.

Stix, G. (2004). Making drugs, not profits. Scientific American, 290(5), 42-4.

Taylor, P. (1995). Co-construction and process: A response to Sismondo's Classification of Constructivisms. Social Studies of Science, 25, 348-359.

Traer, R. (2009). Doing environmental ethics. Boulder, CO: Westview Press.

White, C., Crawford, R., Wood, K., \& Talley, A. (2010, June). Influences and interests in humanitarian engineering. ASEE Annual Conference and Exposition, Conference Proceedings. 
Winner, L. (1986). The whale and the reactor: A search for limits in an age of high technology. Chicago, IL: University of Chicago Press.

Zhang, Q., Vanasupa, L., Zimmerman, J., \& Mihelcic, J. (2010, June). Development and dissemination of learning suites for sustainability integration in engineering education. ASEE Annual Conference and Exposition, Conference Proceedings.

Zinn, H. (1995, July). Hiroshima: Breaking the silence. Open Magazine, (34). Retrieved from http://web.archive.org/web/20071201172331/http://polymer.bu.edu/ amaral/Personal/zinn.html.

Zussman, R. (1985). Mechanics of the middle class: Work and politics among American engineers. Berkeley, Ca: University of California Press. 